\title{
WAYANG WONG DALAM UPACARA DEWA YADNYA DI MRAJAN GDE GRIYA PENIDA, DESA BATUAGUNG, KABUPATEN JEMBRANA
}

\author{
Ni Komang Ayu Putri Sastrini \\ Fakultas Ilmu Agama dan Kebudayaan \\ Universitas Hindu Indonesia \\ Denpasar \\ Ni Wayan Sri Winarti \\ Fakultas Ilmu Agama dan Kebudayaan \\ Universitas Hindu Indonesia \\ Denpasar
}

\begin{abstract}
Wayang Wong dance is a sacred art in which all dancers wear tapels. In the performance, Wayang Wong Dance is a guardian dance, thus the character formation and the structure of the series of performances adjust to the level of yadnya ceremony. In the form of a dance fashion, Wayang Wong still uses traditional clothing, but there are some that are adjusted with the current fashion creations such as the use of gelung, prada cloth. While the dance moves have unique and unique features that are not owned by Wayang Wong that exist in some areas in Bali. Wayang Wong Dance Staging In the ceremony of Lord Yadnya in Mrajan Gde Griya Penida Batuagung village on the main level, usually Wayang Wong staged with a series of ngebejian, stage one round until Wayang Wong perform ngidergita. The percussion used is the gamelan bebatelan Ramayana with staged on the premises of the main mandala or place in the vast grounds.
\end{abstract}

Keywords: Wayang Wong, Implementation of Yadnya God's Ceremony

\begin{abstract}
Abstrak
Tari Wayang Wong merupakan kesenian yang disakralkan yang mana semua penarinya memakai tapel. Dalam pementasan, Tari Wayang Wong merupakan tari wali, dengan demikian bentuk penokohan dan struktur rangkaian pertunjukan menyesuaikan dengan tingkatan upacara yadnya. Dalam bentuk busana tari, Wayang Wong tetap menggunakan busana tradisional namun ada beberapa yang disesuiakan dengan busana kreasi sekarang seperti penggunaan gelung, kain prada. Sedangkan gerak tarinya memiliki ciri khusus dan unik yang tidak dimiliki oleh Wayang Wong yang ada dibeberapa daerah di Bali. Rangkaian pementasan Tari Wayang Wong Dalam upacara Dewa Yadnya di Mrajan Gde Griya Penida desa Batuagung pada tingkat utama, biasanya Wayang Wong dipentaskan dengan rangkaian yaitu dari ngebejian, pentas satu babak sampai dengan Wayang Wong melaksanakan
\end{abstract}


ngidergita. Tabuh yang digunakan adalah gamelan bebatelan Ramayana dengan dipentaskan pada tempat di utama mandala atau tempat dipekarangan yang luas.

Kata Kunci: Wayang Wong, Implementasi Upacara Dewa Yadnya

\subsection{Pendahuluan}

Pulau Bali dengan penduduknya yang sebagian besar beragama Hindu memiliki sosial budaya yang tinggi dan cukup beraneka ragam antara daerah atau desa yang satu dengan daerah atau desa yang lain, sehingga Bali sangat terkenal di manca negara, yang pada akhirnya banyak mendatangkan wisatawan ke pulau Dewata ini.

Agama Hindu mempunyai andil yang besar di bidang seni dan budaya yang bernafaskan agama Hindu. Keindahan yang dijiwai oleh rasa bhakti terhadap Ida Sang Hyang Widhi Wasa, telah melahirkan seni budaya yang bersifat sosial religius. Agama memberikan dorongan dan ilham untuk berkembangnya seni dan budaya yang dimilikinya.

Di samping itu umat Hindu dalam kehidupan sehari-hari selalu diliputi oleh pelaksanaan Yadnya, yang diiringi dengan berbagai bentuk atau jenis upacaranya seperti: Nitia Karma dan Naimitika Karma. Nitia Karma merupakan pelaksanaan Yadnya yang dilakukan setiap hari seperti misalnya: Yadnya Sesa, Tri Sandya dan lainnya. Sedangkan Naimitika Karma adalah pelaksanaan Yadnya yang dilakukan pada waktu-waktu tertentu berdasarkan Desa, Kala, Patra antara lain: Purnama Tilem, Anggara Kasih, Galungan, Kuningan, Nyepi, Saraswati serta Piodalan atau Pujawali. Ini merupakan ucapan puji syukur kepada Tuhan/Ida Sang Hyang Widhi Wasa atau Leluhur.

Pada saat berlangsungnya Piodalan atau Pujawali disebuah Pura atau Mrajan misalnya, di samping mempersembahkan sarana-sarana upacara yang kompleks dan indah. Juga mempersembahkan berbagai macam kesenian yang bersifat sakral (suci) dan magis. Persembahan kesenian tersebut adalah sebagai curahan rasa bhakti kepada Ida Sang Hyang Widhi Wasa serta leluhur.

Dalam ajaran agama Hindu dikenal adanya lima macam Yadnya yang disebut Panca Yadnya, antara lain: (1) Dewa Yadnya, (2) Pitra Yadnya, (3) Rsi Yadnya, (4) Manusa Yadnya dan (5) Bhuta Yadnya. Masingmasing yadnya itu memiliki sarana yang berbeda-beda. Dalam Dewa Yadnya sarananya banyak mengarah kepada Ida Sang Hyang Widhi Wasa atau leluhur. Pada Pitra Yadnya sarana ditujukan kepada para pitara. Sedangkan pada Manusa Yadnya sarana tersebut ditujukan kepada sesama manusia. Dalam Rsi Yadnya sarana ditujukan kepada para Maha Rsi yang telah berjasa mengembangkan ajaran agama. Dan Bhuta Yadnya sarana dipersembahkan kepada alam semesta dan lingkungannya.

Dalam upacara Dewa Yadnya, upacara yang lebih banyak dilaksanakan ditempattempat suci (Pura/Pemerajan). Dengan demikian pelaksanaan upacara Dewa Yadnya selalu berkaitan dengan saranasarana seperti sesajen, yang juga sering disertai dengan berbagai bentuk kesenian misalnya: seni tabuh, seni tari, seni suara atau kidung. Begitu juga halnya juga pelaksanaan Dewa Yadnya di Pura (tempattempat suci) khususnya di desa Batuagung. Dengan demikian sependapat dengan apa yang dinyatakan dalam buku "Palaksanaan Upacara Yadnya" sebagai berikut:

Kalau ada Piodalan atau Pujawali di 
Pura atau di Mrajan, misalnya di Pura Dang Kahyangan, Kahyangan Tiga, Pura Panti, selalu diadakan ilen-ilen seperti: tetabuhan, kekidungan, taritarian serta Wayang Wong yang merupakan tari sakral (suci), dikenal dengan sebagai tari wali yang dalam pementasannya selalu dihubungkan dengan upacara keagamaan dan merupakan salah satu bagian dari pada suatu upacara, (Putra, 1993:3).

Di kalangan masyarakat terutama masyarakat awam masih banyak yang belum secara pasti mengenal tari sakral (Wayang Wong) yang ada di desa adat lainnya. Di Bali banyak terdapat tari-tarian sakral yang belum diketahui oleh masyarakat umum (luas), seperti halnya di Banjar Anyar Desa Batuagung terdapat suatu tarian yang disebut Wayang Wong.

Wayang Wong merupakan sarana untuk mengiringi upacara Dewa Yadnya khususnya di Kahyangan Tiga, Pemerajan, Dangkahyangan dan Dadia. Jika Wayang Wong tidak dipentaskan, maka pelaksanaan upacara dirasakan kurang sempurna atau dianggap tidak lengkap. Oleh karena itu antara Wayang Wong dengan upacara Dewa Yadnya tidak bisa dipisahkan karena tari ini (Wayang Wong) merupakan pelengkap upacara Dewa Yadnya.

Wayang Wong ini sebagai cetusan rasa bhakti kepada Ida Bhatara sebagai Dewa penyelamat. Melihat adanya keunikan Wayang Wong dalam upacara DewaYadnya di Mrajan (tempat-tempat suci) di Desa Batuagung, Kabupaten Jembrana, maka penulis sangat tertarik untuk meneliti Nilai Pendidikan Agama Hindu pada tari Wayang Wong dalam upacara Dewa Yadnya d Mrajan Gde Griya Penida, Desa Batuagung, Kabupaten Jembrana.

\subsection{Metode Penelitian}

Penelitian ini dilakukan di salah satu Mrajan Griye Gde yang bernama Grye Gde Penida sebuah desa yang ada di Kabupaten Jembrana yaitu Desa Batuagung. Hal ini dilakukan berdasarkan pengamatan penulis bahwa hanya di Griye Gde Penida di Banjar Anyar Desa Batuagung, Kabupaten Jembrana ini mempunyai kesenian yang disakralkan yaitu tariWayang Wong. Tapel/ topeng Wayang Wong ini tersimpan rapi pada sebuah gedong yang ada di Merajan Gde Griya Penida, Desa Batuagung Kabupaten Jembrana. Jarak lokasi berkisar antara $1,5 \mathrm{~km}$ dari pusat kota Negara dan sangat mudah di jangkau dari jalan raya Denpasar- Gilimanuk keutara kurang lebih 500 meter.

Metode pengumpulan data penelitian dilakukan dengan tiga jalan yakni wawancara, observasi dan pencatatan dokumen. Teknik wawancara atau sering disebut interview yaitu teknik untuk mendapatkan data dari informaan dengan cara wawancara lisan dengan bercakapcakap berhadapan muka untuk mendapatkan keterangan-keterangan terhadap seseorang, Koentjaraningrat (dalam Ardika 2009:39).

$$
\text { Menurut Mulyana }
$$
wawancara adalah bentuk komunikasi antara dua orang melibatkan seseorang yang memperoleh informasi dari seseorang lainnya dengan mengajukan pertanyaanpertanyaan berdasarkan tujuan tertentu. Wawancara menurut garis besarnya dapat dibedakan menjadi dua yakni wawancara tak terstruktur dan wawancara terstruktur. Wawancara tak terstruktur sering disebut dengan wawancara yang mendalam,wawancara intensif, wawancara kwalitatif dan wawancara terbuka. Sedangkan wawancara terstruktur sering juga disebut wawancara baku yang susunan pertanyaannya sudah disusun dan ditetapkan sebelumnya(biasanya tertulis) dengan 
pilihan-pilihan jawaban yang sudah disediakan.

Berkenaan dengan penelitian yang akan dilakukan dalam meneliti bentuk, fungsi dan makna tari Wayang Wong dalam upacara Dewa Yadnya akan dipergunakan teknik wawancara yang tidak struktural.

Selajutnya adalah observasi. Observasi adalah pengamatan yang dilakukan secara sengaja dan sistematis mengenai fenomena sosial dengan gejala psikis untuk kemudian dilakukan pencatatan (Subagyo, 1999:63). Observasi adalah pengumpulan data yang dilakukan dengan indera dan disertai dengan pencatatan (Sudikan, 1989:36). Observasi terhadap tarian Wayang Wong dilakukan dengan dua cara yakni melakukan pengamatan terhadap wujud tapel dan topeng-topeng yang digunakan. Obsevasi terhadap pertunjukan dilakukan ditempat tari Wayang Wong dipentaskan.

Pencatatan Dokumentasi dilakukan untuk mendapatkan data-data yang terdapat dalam foto-foto dan hasil interview. Dalam penelitian ini sejumlah foto dan hasil interview ditelaah dan dilakukan pencatatan. Sejumlah data-data yang menggandeng makna-makna tertentu juga disampaikan dalam pementasannya pada saat upacara Dewa Yadnya. Sehingga teknik dokumentasi ini dipandang sangat penting dilakukan dalam penelitian ini.

\subsection{Pembahasan}

\subsubsection{Eksistensi Tari Wayang Wong di Mrajan Gde Griya Penida}

Pada Tahun 1812 Ida Ketut Gede (alm) yang lebih dikenal dengan sebutan Kompiang Gedet adalah sosok seniman yang alami tumbuh dan berkembang di sebuah rumah kecil yaitu di Griya Gde Penida, Desa Batuagung, kebetulan beliau itu adalah Kompiang/kakek dari suami penulis. Sebelum melanjutkan sejarah Tari Wayang Wong, lebih awal diterangkan tentang keturunan beliau secara langsung dari garis Purusa sebagai berikut: dari Beliau itu menurunkan Putra Ida Putu Japa (alm) sama seperti bakat ayahnya, beliau juga adalah seniman Wayang Wong yang sangat terkenal memerankan tokoh Rahwana. Dari Ida Putu Japa memiliki Putra Ida Komang Tastra (alm) beliau juga mewarisi bakat ayahnya sebagai penari Wayang Wong, dari Ida Komang Tastra (alm) menurunkan ke putranya yaitu Ida Bagus Rimbawan (suami penulis sendiri). Pada saat itu Ida Ketut Gede alias Kompiang Gedet bersama-sama dengan kawan-kawannya yang semuanya adalah seniman alami membuatlah seperangkat tapel Wayang Wong dalam rangka pelaksanaan upacara agama (piodalan) di tempat suci yang menceritakan tentang epos Ramayana.

Tapel Wayang Wong yang diciptakan oleh Ida Ketut Gede sebanyak 39 (tiga puluh sembilan) jenis yang memiliki corak yang berbeda-beda sesuai dengan karakter tokoh pewayangan. Dalam pembuatan tapel Wayang Wong tersebut digunakanlah bahan dari Kayu Pule agar lebih tahan lama dan memiliki taksu. Sehubungan dengan pembuatan tapel Wayang Wong, maka dilanjutkan dengan pembuatan seperangkat gamelan yang bahannya terbuat dari bambu yang berbentuk seperangkat tingklik.

Setelah gamelan itu selesai dibuat maka Ida Ketut Gede mulailah menghimpun peserta penari (pragina) begitu pula para penabuh termasuk juga pelatihnya. Kemudian sudah lama kesenian Wayang Wong berkembang atas asuhan Ida Ketut Gede, akhirnya belaiu dipanggil Ida Sanghyang Widhi Wasa. Setelah Ida Ketut Gede meninggal maka kepengurusan Wayang Wong dipimpin oleh Ida Bagus Surya (alm). Dari kepemimpinan yang baru ini Wayang Wong sering diundang dalam rangka untuk mengiringi upacara agama bahkan menjadi idola karena pada waktu itu 
hiburan yang lain tidak ada maka otomatis Wayang Wong adalah salah satu kesenian yang diminati oleh masyarakat.

Di samping diundang untuk upacara agama, Wayang Wong juga sering dipentaskan untuk penggalian dana yaitu di sebuah arena atau di sebuah halaman rumah di Desa Batuagung dan sekitarnya termasuk diluar Kecamatan Jembrana seperti di Kecamatan Mendoyo, Pekutatan, Negara dan Melaya. Kemudian tidak berselang lama Beliau Ida Bagus Surya akhirnya meninggal kembali ke alam Ida Sanghyang Widhi Wasa.

Setelah Ida Bagus Surya meninggal maka kepemimpinan Wayang Wong dilanjutkan oleh Ida Putu Japa yang juga Putra dari almarhum Ida Ketut Gede pendiri Wayang Wong. Dalam kepemimpin yang baru itu, dari kepemimpinan Ida Putu Japa akhirnya lama-kelamaan secara berangsurangsur Wayang Wong memiliki seperangkat gamelan bebatelan (gamelan yang terbuat dariperunggu) antara lain: empat buah Gender, dua buah Gupekan / kendang kecil, satu buah Kenong, satu bua Kecek, satu buah Kempul, satu buah Kelenang, dan satu buah Seruling.

Sudah lama berjalan kepemimpinan beliau dan beberapa kali pentas, tampil dalam acara keagamaan maupun untuk hiburan masyarakat, akhirnya beliau Ida Putu Japa akhirnya meninggal karena usia beliau sudah tua. Karena beliau sudah meninggal maka kepemimpinan Wayang Wong dilanjutkan oleh Ida Komang Banjar. Pada waktu kepemimpinan Ida Komang Banjar ada cerita yang sangat menarik yaitu Pemangku Pura Puseh mendengarkan pawisik agar Wayang Wong dipentaskan di Pura Puseh tersebut bilamana di Pura itu ada Pujawali (piodalan). Kemudian Pemangku Pura puseh melaporkan kejadian itu kepada Ida Komang Banjar selaku ketua Sekeha Wayang Wong. Dari laporan itu akhirnya diadakan rapat yang dihadiri oleh pengurus Wayang Wong, pengurus Banjar, Desa dan pemangku. Dari hasil rapat itu disepakati bahwa setiap ada Pujawali/Piodalan di Pura Puseh akan dipentaskan WayangWong dengan mengambil cerita Hanoman duta. Sekitar tahun 1940 Ida Komang Banjar akhirnya meninggal, kemudian kepemimpinan Wayang Wong dilanjutkan oleh Ida Putu Laya (Ida Peranda Gde Griya Penida).

Sejak kepemimpinan Ida Putu Laya, keberadaan dan eksistensi Wayang Wong mengikuti kemajuan jaman, yang mana pada setiap kesenian memiliki nama sekeha, sama sepertisekeha-sekeha kesenian yang lain. Kemudian Wayang Wong di beri nama "Sekeha Wayang Wong Dharma Putra sentana" yang memiliki makna agar para sentana/generasi muda memiliki kewajiban dan tanggung jawab untuk melanjutkan Wayang Wong dimanapun berada dan sampai kapan pun juga tidak akan pernah putus. Setelah Sekeha Wayang Wong memiliki nama akhirnya Ida Putu Laya ingin mengundurkan diri karena usianya sudah tua maka kepemimpinan dilanujtkan oleh Ida Bagus kade Sudamia.

Sejak kepemimpinan Ida Bagus Kade Sudamia Wayang WongDharma Putra Sentana semakin populer bukan saja di lingkungan Jembrana tapi sampai ke tingkat Provinsi Bali melalui Pesta Kesenian Bali. Sekitar Tahun 1984 Wayang Wong Dharma Putra Sentanapertama kali tampil pentas di Art Center Taman Budaya Denpasar dalam Pesta Kesenian Bali yang ke-VI, bahkan waktu itu suami penulis ikut terlibat dalam pagelaran Wayang Wong dengan cerita Hanoman duta, suami penulis masih duduk di bangku SMP kelas III.

Pada waktu itu juga Pemerintah Kabupaten Jembrana di bawah Pemerintahan Bupati Drs. Ida Bagus Ardana, memberikan bantuan dana kepada Wayang Wong Dharma 
Putra Sentana untuk merangsang agar kesenian sakral ini dapat dilestarikan.Sekitar tahun 1987 kepemimpinan Wayang Wong dilanjutkan oleh Ida Bagus Putu Putra sampai sekarang. Dari kepemimpinan Ida Bagus Putu Putra Wayang Wong sudah berkali-kali ditampilkan dalan ajang Pesta Kesenian Bali, baik dalam bentuk pagelaran maupun untuk parade. Disamping itu pula Wayang Wong mengalami perubahan sesuai dengan kemajuan jaman yaitu dalam bentuk busana, dimanadulu Wayang Wong hanya memakai busana tradisional khas berupa kain-kain tenunan gringsing, rembang, selendang kuno, gelung ukiran kuno dan lain-lain, namun sekarang sudah mengalami perubahan yaitu busananya ditambah dengan kain-kain prade, gelung prade dan lain-lain.

\subsubsection{Bentuk Tari Wayang Wong di Banjar Anyar Desa Batuagung \\ 1. Tata Gerak \\ Wayang Wong Dharma Putra Sentana} yang ada di Desa Batuagung ini memiliki keunikan dan kekhasan dalam gerak tari, berbeda dengan Wayang Wong yang ada di beberapa tempat di Bali. Masing-masing tokoh dalam Wayang Wong ini memiliki gerak tari yang berbeda-beda terutama dalam tokoh pasukan kera dan tokoh pasukan raksasa ada pakem yang harus diikuti dan dipatuhi oleh setiap penari/ pragina. Hanya saja untuk tokoh Rama, Sinta, Laksaman,sedang punakawannya hampir tidak ada perbedaan gerak dan tarinya. Khusus untuk tokoh pasukan kera dan raksasa akan penulis jelaskan sebagai berikut:

(1) Sugriwa, Jembawan, Hanoman, Ngada, Nila, Sang nala, Nala Gni, menurut Putra (wawancara 9/12/2014) gerak tarinya sama ada disebutkan dengan istilah Nyamir, Nayog dan Nyeregseg. Menurut Nandi (wawancara 10/12/2014) untuk tokoh yang agak tua seperti Sugriwa dan Jembawan kebanyakan menggunakan gerakan tari nyamir yaitu tangan kiri berada di depan dada, kemudian tangan kanan berayun kesamping kembali lagi didepan dada, posisi kaki dalam keadaan ngagem. Gerakan nyeregseg yaitu kaki kanan dan kiri digetarkan sambil berjalan. Sedangkan gerakan nayogadalah memainkan gerakan pantat kesamping kanan dan kiri dengan posisi tetap dalam keadaanngagem. Untuk tokoh tua seperti Jembawan dan Sugriwa menggunakan gerakan tari yang sering digunakan adalah nyamir dan kadangkadang nyeregseg karena gerakan nyamir tidak banyak menggunakan tenaga gerak sehingga cocok untuk tokoh yang usianya tua. Sedangkan untuk gerakan nayog dan nyeregseg lebih banyak dimainkan oleh tokoh yang energik seperti Hanoman, Ngada, Nila, Sang Nala, Nalagni dan yang sejenisnya.

(2) Mongmuka dan Wirasabha, menurut Jember (wawancara 11/12/2014) gerak tarinya adalah memainkan kaki mengikuti gerakan seekor Penyu dan seekor Harimau yaitu kaki kanan diangkat terus silih berganti kaki

kiri, posisi tangan ngagem. Jika kaki kanan di angkat maka tangan kiri lurus ke samping dan tangan kanan ditekuk berada di samping dada, begitu pula sebaliknya jika kaki kiri diangkat maka tangan kanan lurus ke samping dan tangan kiri ditekuk berada di samping dada sebelah kiri, demikian seterusnya silih berganti.

(3) Sempati, Gowaksa dan Jatayu, Menurut Mantra (wawancara 15//12/2014) gerak tarinya adalah mengikuti gerakan seekor burung yaitu menggerak-gerakkan sayapnya. Khusus untuk tokoh Sempati dan Jatayu ini memiliki gerak yang khas yang mana posisinya adalah badan 
kaki ngoos bergerak kesamping kanan dan kiri, tangan kanan naik keatas di gerak-gerakan sedangkan tangan kiri kebawah juga digerak-gerakan, setelah satugerakan selesaikemudianberganti tangan kiri diatas di gerak-gerakkan tangan kanan kebawah juga digerakgerakan. Setelah dua gerakan yaitu kesamping kanan satu kali kesamping kiri satu kali maka gerakan maju ke depan dengan cara nyeregseg.

(4) Menda, meurut Suliksa (wawancara 2/01/2015) gerak tarinya adalah meniru gerak tari seekor Sapi, Kambing atau yang sejenis karena Menda tiada lain adalah seekor Sapi. Tokoh ini harus ditarikan oleh orang yang tenaganya besar karena gerakan tarinya banyak berlari, lari di tempat. Posisi gerak tarinya adalah kepala menyenggol-nyenggol, tangan kiri dan kanan ngagem satu lurus kedepan satunya lagi di samping dada, posisi kaki terus bergerak kadang-kadang berlari kadang-kadang lari ditempat.

Sedangkan untuk gerak tari pada pasukan di pihak Rahwana yaitu pasukan Raksasa semuanya posisi gerak tarinya hampir sama, hanya saja yang membedakan adalah jika raksasa itu raja dan patih berbeda dengan raksasa bawahan/abdi. Untuk lebih jelasnya penulis akan jelaskan satu persatu gerak tari masing-masing tokoh Raksasa sebagai berikut:

(1) Raksasa Rahwana dan Meganada, menurut Medra (wawancara 3/01/2015) gerak tarinya adalah kebanyakan posisi tangannya menyentuh kepala dan dada. Jika tangan kanan naik ketas menyentuh kepala maka tangan kiri menyentuh dada, silih berganti. Kemudian jika berjalan memakai agem kanan dan kiri seperti ngagem raksasa, dengan jari- jari tangan terbuka.

(2) Patih Prahasta, Patih Marica menurut Jayus (wawancara 4/01/2015) gerakan tarinya adalah kadang-kadang posisi tangannya ketas menyentuh kepala, kemudian kalau berjalan nyeroscos yaitu kedua tangan berada di depan digerak-gerakan dengan jari-jari tangan terbuka sedangkan kakinya tetap posisi ngagem jika berjalan mengikuti suara kenong.

(3) Raksasa Prajangga, Bububris, Kolekati dan yang sejenisnya Nadia (wawancara 5/01/2015) adalah raksasa sejenis bawahan maka gerakan tarinya tidak sama dengan Raja atau pun patih, cukup posisi agem yang mana tangan nyeroscos saja yaitu kedua tangan berada di depan dengan jari tangan terbuka kemudian digetarkan, kaki berjalan mengikuti suara kenong.

\section{Tata Busana dan Kelengkapan}

Setiap tokoh dalam Wayang Wong memiliki busana yang berbeda sesuai dengan peran dan karakternya masingmasing seperti :

(1) Tapel Rama: warna tapel adalah hijau, busana warna hijau dari atas adalah gelung raja, badong, gelang kana, sabuk, ampok, kain, celana, gelang kana pada kaki, ditambah selendangselendang klasik, dilengkapi busur dan anak panah.

(2) Tapel Laksmana: warna tapel agak kekuning-kuningan, busana warna kuning, dengan kelengkapannya seperti dari atas gelung metanduk, badong, gelangkana tangan, sabuk,ampok, kain klasik, selendang klasik, celana, gelangkana kaki, lengkap dengan busur dan anak panah.

(3) Tapel Dewi Sita: warna tapel adalah agak putih, busana dari atas adalah 
gelung putri, sumpel, badong, gelangkana, badong lelamakan, sabuk/stagen prada, ampok, kain prada panjang, selendang klasik/ tradisional.

(4) Tapel Tualen: warna dan bentuk tapel adalah coklat kehitaman, busana dari atas gelung mekuncir, rumbing, badong kecil, baju celana warna hitam, kain/kamben hitam,saput gede warna hitam-poleng, bantal kecil di leher dan perut.

(5) Tapel Merdah: warna dan bentuk tapel adalah coklat kehitaman, busana dari atas adalah gelung mekuncir, rumbing, badong kecil, baju dan celana warna merah, saput gede warna hitampoleng, kain/kamben warna merah, bantal kecil di perut.

(6) Tapel Sugriwa: warna tapel adalah merah, bentuk tapel menyerupai kera lengkap dengan rumbing (hiasan diatas tapel menempel pada gelung) dan gelung patih, busana dari atas adalah badong gede, gelangkana tangan, training warna merah, bulu dada warna merah, ampok, ekor warna merah, sabuk, kain warna merah kotak, stewel kaki.

(7) Tapel Hanoman: warna tapel adalah putih susu, bentuk menyerupai kera, tapel dilengkapi dengan rumbing, gelung bertanduk, busana : badong, bulu dada warna putih, gelang kana tangan, training warna putih, sabuk, selendang putih, kain poleng, ampok, ekor warna putih, gelang kana kaki.

(8) Tapel Jermbawan: warna tapel agak kebiru-biruan lengkap dengan rumbing, gelung mebawa raja, bentuk tapel menyerupai kera, busana: badong, gelang kana tangan, buludada warna biru, training warna biru, sabuk, selendang-selendang, ampok, ekor warna biru, stewel kaki.
(9) Tapel Ngada: warna tapel adalah merah lengkap dengan rumbing dan gelung bertanduk, bentuknya menyerupai kera, busana : dari atas adalah Badong,bulu dada warna merah, gelangkana tangan, training warna merah, kain kotak warna merah, selendang-selendang, ampok, ekor warna merah, stewel kaki.

(10) Tapel Nila: warna tapel adalah hijau, lengkap dengan hiasan rumbing dan gelung bertanduk, bentuknya menyerupai kera, busana: dari atas adalah badong,gelang kana tangan, bulu dada warna hijau, training warna hiaju, sabuk, selendang-selendang, ampok, ekor warna hijau, stewel kaki.

(11) Tapel Nalagni: warna tapel adalah merah, lengkap dengan rumbing dan gelung bertanduk api, bentuk menyerupai kera, busana: dari atas adalah badong, gelangkana tangan, bulu dada warna merah, training warna merah, sabuk, kain merah kotak, ampok, ekor wana merah, stewel kaki.

(12) Tapel Menda: warna tapel adalah kuning berisi bintik-bintik hitam, lengkap dengan rumbing dan gelung bertanduk seperti Sapi, bentuk menyerupai seekor Sapi, busana: dari atas adalah badong, gelangkana tangan, bulu dada warna kuning, training warna kuning bintik-bintik hitam, kain warna poleng, selendangselendang, sabuk, ampok, ekor warna putih kekuning-kuningan, stewel kaki.

(13) Tapel Jatayu, Gowaksa dan sempati: warna tapel adalah biru, hijau lengkap dengan rumbing dan gelung tanpa tanduk, bentuk tapel menyerupai seekor burung raksasa, burung elang dan garuda, busana: dari atas adalah badong, gelangkana tangan, bulu dada warna biru, training warna biru, sayap, kain, ampok, selendang-selendang, 
stewel kaki.

(14) Tapel Mong Muka: warna tapel adalah merah, lengkap dengan hiasan rumbing dan gelung tanpatanduk, bentuknya menyerupai seekor Macan/Harimau, busana: badong,gelangkana tangan, bulu dada merah, training warna merah, selendang-selendang, kain merah, ekor merah, ampok, stewel kaki.

(15) Tapel Wirasaba: warna tapel adalah merah, lengkap dengan rumbing dan gelung tanpa tanduk, bentuknya menyerupai seekor Penyu, busana: dari atas adalah badong, gelangkana tangan, bulu dada warna merah, training warna merah, sabuk, selendang-selendang, ekor warna merah, ampok, stewel kaki.

(16) Tapel Rahwana: warna tapel hitam kecoklatan, lengkap dengan rumbing dan gelung raja, bentuknya menyerupai raksasa bertaring gigi tidak rata, busana: dari atas adalah badong gede, saput gede, kain putih, baju merah prade, sabuk,celana putih, stewel kaki.

(17) Tapel Meganada: warna tapel hitam kecoklatan, lengkap dengan rumbing dan gelung bertanduk, bentuknya menyerupai raksasa mirip dengan Rahwana ayahnya bertaring namun giginya rata, busana; dari atas adalah badong gede, saput gede, baju hitam, gelang kana tangan, kain putih, sabuk, celana putih, stewel kaki.

(18) Tapel Delem: warna tapel adalah merah kekuning-kuningan, lengkap dengan rumbing dan gelung berisi jambul, bentuk tapel besar dengan gondoknya di leher, busana: dari atas, badong gede, saput gede, kain merah, sabuk, baju dan celana merah.

(19) Tapel Sangut: warna tapel adalah kuning, lengkap dengan rumbing dan gelung berisi kuncir, bentuknya lancip ada jenggotnya sedikit, lehernya panjang (gulu dawa), busana: dari atas badong kecil, saput gede, baju dan celana warna kuning, kain putih, sabuk.

(20) Tapel Prahasta/patih Prahasta: warna tapel adalah kuning susu, lengkap dengan hiasan rumbing dan gelung patih, bentuknya menyerupai raksasa, busana: dari atas adalah badong gede, saput gede, baju dan celana warna putih,kain putih, sabuk, stewel kaki.

(21) Tapel Marica: warna tapel adalah coklat, lengkap dengan hiasan rumbing dan gelung patih, bentuknya menyerupai raksasa, busana: dari atas adalah badong gede, saput gede, gelangkana tangan, baju dan celana poleng, sabuk kain putih Stewel.

(22) Tapel Prajangga: warna tapel adalah merah kehitaman, lengkap dengan hiasan rumbing dan gelung patih, bentuknya menyerupai raksasa, busana: dari atas adalah badong gede, saput gede, baju dan celana warna poleng, kain putih, stewel.

(23) Tapel Bububris: warna tapel adalah warna hitam kecoklatan, lengkap dengan hiasan rumbing dan gelung patih, bentuknya menyerupai raksasa, busana: dari atas adalah badong gede, saput gede, baju dan celana poleng, kain putih, stewel.

(24) Tapel Raksasa Rongong: warna tapel hitam ke abu-abuan, lengkap dengan hiasan rumbing dan gelung, bentuknya menyerupai raksasa giginya ompong, busana: badong, saput gede, baju dan celana warna poleng. Kain poleng, sabuk.

\section{Tata Iringan}

Untuk pertama kali berdiri Wayang Wong hanya mempergunakan gamelan tingklik yang terbuat dari bahan bambu, 
namun setelah mengalami kemajuan dari generasi ke generasi akhirnya sampai sekarang Wayang Wong sudah memiliki gamelan dengan menggunakan Bebatelan yaitu terdiri dari :

- 4 buah gender

- $\quad 2$ buah kendang kecil

- 2 buah kendang besar

- 1 perangkat kecek

- 1 buah kempul

- 1 buah kenong

- 1 buah klenang

- $\quad$ Seperangkat seruling.

Dalam setiap pementasanWayang Wong, semua perangkat gamelan diatas selalu di gunakan sehingga gamelan Wayang Wong nampaknya semakin meriah (rame) sehingga cocok dengan namanya Rameyana menjadi Ramayana.

\section{Tata Ucapan/Gending Penggalang}

Di samping kekhasannya berupa busana dan gerak tarinya, Wayang Wong Dharma Putra Sentana juga memilki ke unikan dan kekhasan tersendiri dalam ucapan/tekanan suara maupun gending yang digunakan dalam setiap pementasan jika dibandingkan dengan kesenian Wayang Wong yang ada di beberapa daerah di Bali. Setiap tokoh dalam pementasan Wayang Wong memiliki masing-masing gending tersendiri yang semua syairnya kebanyakan diambil dari Kakawin Ramayana. Sedangkan ucapan atau tekanan suara juga dibedakan setiap tokoh baik itu punakawan, dewi, raja, rakyat, raksasa dan lain-lain.

Jika tokoh itu wanita dan raja seperti Dewi Sinta, Trijata dan Rama,Laksamana, Wibisana memakai tekanan suara yang agak halus dan agak dipanjangkan dialeknya (mengeok). Sedangkan tokoh yang lain Pasukan Kera dan Raksasa mengikuti karakter masing-masing. Untuk Punakawan tualen, Merdah, Sangut dan Delem juga menyesuaikan dengan karakternya masing- masing. Dibawah ini akan diuraikan satu per satu tentang ucapan dan gending masingmasing tokoh yang digunakan dalam pementasan Wayang Wong sebagai berikut :

(1) Tualen dan Merdah, pertama tampil namun sebelum keluar atau membuka rangkai kedua penari harus menyanyi atau mapengalang sebagai berikut: "Gawa-gawa gowaksa jembawa.............." sang Jatayu manuk mageng........". kemudian dilanjutkan dengan ucapan-ucapan, Tualen: "Dah...? lautang-lautang pejalan nanang kelawan cai...". Dijawab oleh Merdah: "Cang.. nanang, jalan nang...".

(2) Rama dan Laksmana, sebelum membuka rangki/langse penari terlebih dahulu menyanyi atau disebut dengan mapengalang sebagai berikut: "Wibisana kapindra maruti...., sang jatayu manuk mageng.......... ”. Setelah selesai menyanyi / mepengalang maka dilanjutkan dengan ucapanucapan atau dialog di dalam rangki atau langse sebagai berikut: Rama : "lah ta kita yayi.......". tumut pemargan de twanta..." dijawab oleh laksmana : "henak paduka ya kaka.......". setelah selesai semuanya itu barulah Rama dan Laksmana keluar atau membuka rangki/langse. Setiap kali berjalan keduanya bernyanyi/ mapengalang.

(3) Sugriwa, sebelum membuka rangki penari mapengalang atau menyanyi sebagai berikut: "Wara mitra rakan dewi......, sang Sugriwa ratuning wre...". setelah selesai mapengalang barulah penari Sugriwa keluar rangki. Setiap berjalan penari terus mapengalang, makanya penari diharapkan mampu melantunkan kakawin.

(4) Nila dan Ngada, sebelum membuka 
rangki terlebih dahulu mapengalang sebagai berikut: "He... kang Nila haywa humeneng...Sang sugriwa rwang nira...". Setelah selesai mapengalang barulah penari Nila dan Ngada membuka rangki, menari sambil mapengalang lagi.

(5) Gowaksa, Sempati dan Jatayu, sebelum penari membuka rangki terlebih dahulu menyanyi/ mapengalang sebagai berikut: "Gawagawa gowaksa, jambawa..., Sang Jatayu manuk mageng....". setelah selesai mapengalang barulah membuka rangki, dilanjutkan dengan menari sambil mapengalang lagi.

(6) Mongmuka, Wirasaba dan Menda, sebelum membuka rangki penari harus terlebih dahulu mapengalang sebagai berikut: "Menda muka mwang sempai...., Sang Jatayu manuk mageng....".

(7) Hanoman, sebelum membuka rangki sang penari terlebih dahulu mapengalang sebagai berikut: "He kang Nila haywa humeneng......, Sang marutsuta ngaran nira........". Setelahselesai mapengalang barulah sang penari membuka rangki seraya menari sambil mapengalang lagi, "patihkumatih patikanang rat sang pawana tmaja ngagegana..., he marutsuta mararian ta, iki poh ceroring, langsat, enak mangan ta kita...".

(8) Jambawan, sebagai tokoh tua biasanya paling belakang dia keluar dalam pementasan, namun sebelum keluar penari terlebih dahulu mapengalang sebagai berikut: "Wara mitra rakan dewi..., sang jambawan ngaran nira...". Demikian juga selanjutnya setelah selesai mapengalang barulah membuka rangki, seraya menari diiringi pengalang.
Di pihak pasukan Rahwana para penari mapengalang sedikit berbeda kebanyakan syair pengalangnya diambil dari kakawin arjuna wiwaha, dengan satu persatu tampil dalam pertunuukan sebagai berikut :

(1) Delem dan Sangut, sebelum membuka rangki Delem mapengalang dengan pengalang yang kocak karangan sendiri yang berpantun seperti : "pulpul kedul ayu dodol jumah dane dempul....rujak bunut mari katon siri rembang gentorek sin tok belok......pul sinoge jukut timbul basang gede.... plag idadong nep-ung caplug tuke..."dan seterusnya. Setelah selesai Delem membuka rangki sambil bernyanyi, kemudian dilanjutkan dengan sangut bernyanyi biasanya menggunakan sekar alit sebagai berikut:"dabdabangdewadabdabang, mumpung dewa kari alit..".dan seterusnya.

(2) Rahwana, mapengalang sebelum membuka rangki sebagai berikut: "Ambek sang paramartha pandita, huwus limpad sakeng sunyata setelah selesai mapengalang barulah membuka rangki diikuti dengan tari dan mapengalang diisi dengan ucapan suara menggelegar (ngerak).

(3) Raksasa raksasa pasukan Rahwana seperti Meganada, patih Prahasta, patih Marica, Prajangga, Bububris, Kolekati adalah semuanya mapengalang Kakawin Arjuna Wiwaha dalam wirama sardula wikridita seperti: "Ambek sang paramarta pandita..., huwus limpad sakeng sunyata..., tan sangkeng wisayaprayojananira..., lwir sanggraheng lokika..."dan seterusnya.

(4) Dewi Sinta dan Tri jata, sebelum membuka rangki penari biasanya terlebih dahulu mapengalang sebagai berikut: "Tan sah menangis diah 
Janakai...., Rama Badra di dira mana...". $\quad$ selesai mapengalang dilanjutkan dengan ucapan-ucapan dari Dewi Sinta:"Lah ta kita paricarika..., tumut pamargan de twanta...? dijawab oleh Tri jata: "henak paduka ya kaka...". Kemudian setelah itu barulah keduanya membuka rangki disertai dengan gerak tari dan nyanyian pengalang.

\section{Ritual Sebelum Pementasan Tari Wayang Wong}

Sebelum pementasan Wayang Wong biasanya pemangku atau yang melaksanakan yadnya terlebih dahulu mapiuning di pura - pura serta memberitahukan kepada warga akan dipentaskan Wayang Wong dalam rangka upacara Piodalan/Dewa Yadnya. Setelah itu maka ketua sekeha memberitahukan pada anggota sekeha. Dua hari sebelum puncak piodalan sekeha Wayang Wong harus sudah menerima banten taksu, setelah tanda jadiberupa banten taksu maka ketua sekeha melanjutkan matur piuning di tempat penyimpanan Wayang Wong dengan sarana upakara sebagai berikut: Tipat daksina, canang gantal, tumpeng putih kuning, punjung rayunan, segehan dilengkapi wangi-wangian.

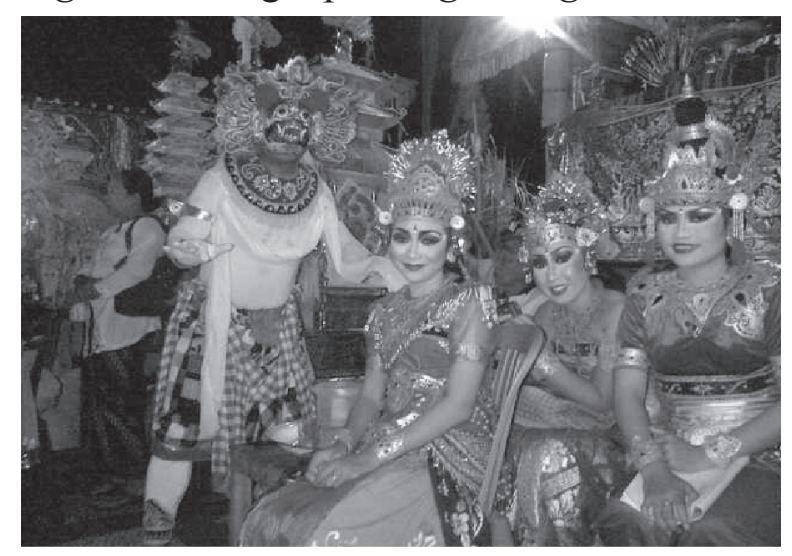

Wayang Wong sebelum pentas

Sebelum pementasan para penari membawa tapel wayang diperciki tirta pebersihan dan pengelukatandisetai pareresikan matepung tawar. Di Mrajan Gde Griya Penida tempat pementasan sudah siap dengan banten arepan Wayang Wong sebagai tanda bahwa Wayang Wong memiliki nilai kesakralan atau kesucian yang tinggi serta untuk memohon keselamatan baik penari maupun yang beryadnya.

Rangkaian upacara Dewa Yadnya tingkatannya besar/utama maka ada rangkaian pementasan Wayang Wong yang patut di laksanakan ada tiga tahapan yaitu : (1) Mabejian, (2) lelampahan, (3) ngidergita. Adapun rangkaian pertunjukan Wayang Wong akan penulis uraikan sebagai berikut:

\section{Ngebejian}

Tahapan pertama dalam rangka ngebejian : posisi dari depan ada batang tebu, padupan, keris, umbul-umbul, payung, bendera, senjata dewata nawa sanga, Wayang wong, deeng, pengawin-pengawin, nyasan Ida Batara, gong, krama pekandel.

\section{Pementasan Wayang Wong}

Tahapan kedua berupa Pementasan Wayang Wong, setelah datang dari ngebejian maka dilanjutkan dengan pementasan Wayang Wong satu babak/satu lalampahan, biasanya mengambil cerita Sang Rama akan melaksanakan yadnya besar, dalam yadnya nanti akan memerlukan daging suci untuk perlengkapan yadnya yaitu dari kijang putih, klesih, keker, babihutan, landak dan lainlain. Untuk mensukseskan yadnya beliau maka diutuslah para pasukan kera untuk mencari binatang suci tersebut.

Sang Sugriwa memerintahkan Hanoman, Ngada, Nila, Nalagni, Mong Muka, Sempati, Wirasaba, Gowaksa pergi kehutan atau ke laut untuk mendapatkan binatang suci tersebut, namun dalam perjalanan para pasukan kera itu dihadang oleh para raksasa pasukan Rahwana.

Dalam perjalanan itulah terjadi perang 
hebat antara pasukan kera yang dipimpin Hanoman dengan para Raksasa. Tidak berlangsung lama semua pasukan Raksasa dapat dikalahkan dan dipukul mundur, sehingga pasukan kera dapat kembali ke tenpat Sri Rama seraya menghaturkan hasil buruannya masing-masing. Dengan keberhasilan itu Sri Rama sangat gembira, dengan demikian akhirnya yadnya beliau dapat dilaksanakan dengan baik dan sukses. Demikian cerita satu babak yang biasanya pementasan pada waktu upacara Dewa Yadnya di Mrajan Gde Griya Penida.

\section{Ngidergita}

Tahapan upacara berupa acara ngidergita, setelah selesai pementasan satu babak maka dilanjutkan dengan yang terakhir sebagai penutup pementasan Wayang Wong adalah tahapan ngidergita yaitu semua para penari Wayang Wong menaiki Bale Pawedan dengan duduk melingkar ada suguhan/bhoga. Namun sebelum menikmati suguhan tersebut terlebih dahulu para penari matembang/ makekawin silih berganti sesuai dengan kemampuan masing-masing. Setelah semua mendapatkan giliran yaitu satu putaran maka upacara ngider gita sudah selesai maka dilanjutkandengan menikmati suguhan yang telah disediakan. Dengan demikian berakhirlah rangkaian pementasan Wayang Wong dalam upacara Dewa Yadnya.

Setelah selesai maka para penari kembali menaruh tapel Wayang Wong terlebih dahulu di prayascita kemudian dilengkapi dengan segehan agung termasuk para penari kembali di prayascita agar mendapatkan kesucian dan anugrah keselamatan.

Tempat pementasan atau juga disebut "kalangan" dalam istilah Bali adalah tempat pertunjukan yang merupakan faktor terpenting dalam mengadakan suatu pementasan, baik untuk teater tradisional maupun teater modern. Pementasan Tari Wayang Wong di Mrajan Gde Griya Penida Banjar Anyar, Desa Batuagung di selengarakan jika saat piodalan/upacara Dewa Yadnya yang utama/besar. Pementasan Wayang Wong dilaksanakan di Utama Mandala Mrajan Griya Penida. Penari keluar dari barat menghadap ke timur, dan para semeton atau penonton memenuhi areal Utama Mrajan Gde Griya Penida Banjar Anyar, Desa Batuagung.

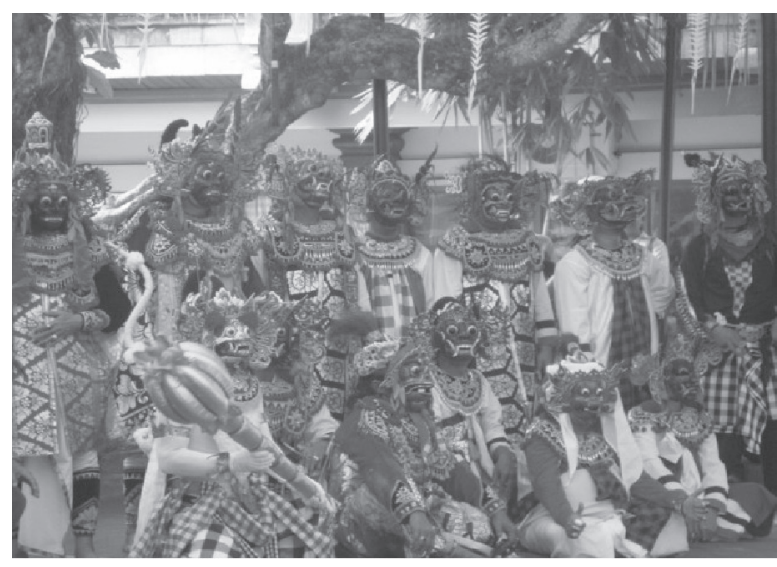

Personel Wayang Wong

\subsection{Penutup}

Tari Wayang Wong merupakan kesenian yang disakralkan yang mana semua penarinya memakai tapel. Dalam pementasan, Tari Wayang Wong merupakan tari wali, dengan demikian bentuk penokohan dan struktur rangkaian pertunjukan menyesuaikan dengan tingkatan upacara yadnya. Dalam bentuk busana tari, Wayang Wong tetap menggunakan busana tradisional namun ada beberapa yang disesuiakan dengan busana kreasi sekarang seperti penggunaan gelung, kain prada. Sedangkan gerak tarinya memiliki ciri khusus dan unik yang tidak dimiliki oleh Wayang Wong yang ada dibeberapa daerah di Bali. Rangkaian pementasan Tari Wayang Wong Dalam upacara Dewa Yadnya di Mrajan Gde Griya Penida desa Batuagung pada tingkat utama, biasanya Wayang Wong 
dipentaskan dengan rangkaian yaitu dari ngebejian, pentas satu babak sampai dengan Wayang Wong melaksanakan ngidergita. Tabuh yang digunakan adalah gamelan bebatelan Ramayana dengan dipentaskan pada tempat di utama mandala atau tempat dipekarangan yang luas.

\section{DAFTAR PUSTAKA}

Adia Wiratmaja, G. K. 1998. Etika, Tata Susila Hindu Dharma. Denpasar. Bertens, K. 1992. Etika. Jakarta: Gramedia Pustaka Utama.

Mantra, I. B. 1996. Landasan Kebudayaan Bali. Denpasar: Yayasan Dharma Sastra.

Nala. Ngurah dan Wiratmaja. 1989. Murdha Agama Hindu. Denpasar: Upada Sastra.

Nawawi, Hadari. H.1995. Metode Penelitian Bidang Sosial. Yogyakarta: Gajah Mada University press.

Parisada Hindu Dharma Pusat, 1989/1990. Himpunan Seminar Kesatuan Tafsir Terhadap Aspek-Aspek Agama Hindu I-IV. Jakarta.

Sura, I Gede (ed). 2001. Pengantar Agama Hindu di Bali. Denpasar: PHDI
Kota Denpasar.

Subagyo, Joko. 1991. Metode Penelitian Suatu Metode Dan Praktek. Jakarta: Rieneka Cipta.

Sudarsana, I. B. Putu. 2002. Ajaran Agama Hindu Filsafat Yadnya. Denpasar: Yayasan Dharma Acarya.

, I. B. Putu. 2003. Ajaran Agama Hindu Acara Agama. Denpasar: Yayasan Dharma Acarya. , I. B. Putu. 2000. Ajaran Agama Hindu. Denpasar: Yayasan Dharma Acarya.

Sudikan, Setya Yuwana. 1989. Penuntun Karya Ilmiah, Semarang, Aneka Ilmu.

Poerwanto, Hari. 2000. Kebudayaan dan Lingkungan Dalam Perspektif Antropologi. Yogyakarta: Pustaka Pelajar.

Poerwardarminta, WJ. S. 1996. Kamus Besar Bahasa Indonesia. Jakarta: Balai Pustaka.

Siwananda, Swami. 1997. Intisari Ajaran Hindu. Surabaya: Paramita.

Triguna, I. B. Gede Yudha. 2000. Teori Tentang Simbol. Denpasar: Widya Dharma. 